\title{
(息)
}

Citation:

Brymer, E and Schweitzer, R (2013) The search for freedom in extreme sports: A phenomenological exploration. Psychology of Sport and Exercise, 14 (6). 865 - 873. ISSN 1469-0292 DOI: https://doi.org/10.1016/j.psychsport.2013.07.004

Link to Leeds Beckett Repository record:

https://eprints.leedsbeckett.ac.uk/id/eprint/2606/

Document Version:

Article (Accepted Version)

The aim of the Leeds Beckett Repository is to provide open access to our research, as required by funder policies and permitted by publishers and copyright law.

The Leeds Beckett repository holds a wide range of publications, each of which has been checked for copyright and the relevant embargo period has been applied by the Research Services team.

We operate on a standard take-down policy. If you are the author or publisher of an output and you would like it removed from the repository, please contact us and we will investigate on a case-by-case basis.

Each thesis in the repository has been cleared where necessary by the author for third party copyright. If you would like a thesis to be removed from the repository or believe there is an issue with copyright, please contact us on openaccess@leedsbeckett.ac.uk and we will investigate on a case-by-case basis. 


\section{The Search for Freedom in Extreme Sports: A Phenomenological Exploration}

\section{Abstract}

Participation in extreme sports is continuing to grow, yet there is still little understanding of participant motivations in such sports. The purpose of this paper is to report on one aspect of motivation in extreme sports, the search for freedom. The study utilized a hermeneutic phenomenological methodology. Fifteen international extreme sport participants who participated in sports such as BASE jumping, big wave surfing, extreme mountaineering, extreme skiing, rope free climbing and waterfall kayaking were interviewed about their experience of participating in an extreme sport. Results reveal six elements of freedom: freedom from constraints, freedom as movement, freedom as letting go of the need for control, freedom as the release of fear, freedom as being at one, and finally freedom as choice and responsibility. The findings reveal that motivations in extreme sport do not simply mirror traditional images of risk taking and adrenaline and that motivations in extreme sports also include an exploration of the ways in which humans seek fundamental human values.

Key words: Extreme Sports, Freedom, Phenomenology, Motivation 


\section{The Search for Freedom in Extreme Sports: A Phenomenological Exploration}

\section{Introduction}

Over the past two decades, participation rates in extreme sports and their less extreme cousins have grown exponentially far outstripping the growth rates of many traditional sporting activities (American Sports Data, 2002; Pain \& Pain, 2005). According to Puchan (2004) involvement in extreme sports is not "just a 'flash in the pan' but a sign of the times" (p.177). Examples of extreme sports include a parachute activity known as BASE (an acronym of Building, Antenna, Span, Earth) jumping, waterfall kayaking, big wave surfing, climbing without ropes and extreme skiing where the most likely outcome of a mismanaged mistake or accident is death (Brymer, 2005).

There is a widely held and theory-driven presupposition that extreme sports are synonymous with risk and participation tantamount to risk taking or adrenaline seeking (Brymer, 2002; Delle Fave, Bassi, \& Massimini, 2003; Lambton, 2000; Monasterio, Mulder, Frampton, \& Mei-Dan, 2012; Olivier, 2006; Pizam, Reichel, \& Uriely, 2002; Rinehart, 2000; Self, Henry, Findley, \& Reilly, 2007; Simon, 2002). From this traditional perspective, participation in extreme sports is most often judged as pathological, socially unacceptable, negative, and deviant (Elmes and Barry, 1999; Monasterio, 2007; Pain and Pain, 2005; Self et al., 2007). Participants are frequently described as selfish teenage boys who are "fascinated with the individuality, risk, and danger of the sports" (Bennett, Henson, and Zhang, 2003, p. 98).

The dominant theories focus on psychological and sociological explanations. These perspectives propose that personality traits (e.g., Breivik, 1996; Hunt, 1996; Self et al., 2007), socialization processes (e.g., Allman et al., 2009; Fletcher, 2008; Laurendeau, 2008), and previous experiences work to compel a participant to put his or her life at risk through extreme sports (Brymer, 2010). The main psychological theories include type T (Self et al., 
2007), psychoanalysis (Hunt, 1996), and sensation seeking (Breivik, 1996; Goma, 1991; Robinson, 1985; Rossi and Cereatti, 1993; Schrader and Wann, 1999; Shoham, Rose, and Kahle, 2000; Slanger and Rudestam, 1997; Straub, 1982; Zarevski et al., 1998; Zuckerman, 2007).

Those espousing type $\mathrm{T}$ theory explain participation in extreme sports as the realization of a deviant personality trait (Self et al., 2007) and a need for uncertainty, novelty, ambiguity, variety, and unpredictability (Farley, 1991). The psychoanalytic perspective (Elmes and Barry, 1999; Hunt, 1996) has been used to categorize participation in extreme sports as a pathological and unhealthy narcissistic tendency in which participants are “denying limitations and vulnerabilities, rationalizing unacceptable behavior and feelings, overestimating abilities and accomplishments, and offering consistently self-serving explanations for successes and failures" (Elmes and Barry, 1999, p. 165). The sensationseeking standpoint has been used to argue that participation in extreme sports is driven by an inbuilt need for novel experiences and intense sensations (Rossi and Cereatti, 1993; Schroth, 1995). Participants continually search for new outlets to obtain thrills and excitement and alleviate boredom. From these theoretical, risk-taking perspectives extreme sports participation is: 1) the realization of a deviant trait; 2) a pathological and unhealthy activity that results in self deception; and 3) a hedonistic activity where death is played with for thrills and excitement. However, this approach may be too simplistic (Brymer, 2010). Pain and Pain (2005) wrote that extreme sport participants are careful, disciplined, well trained, well prepared, and self-aware:

Despite the public's perception, extreme sports demand perpetual care, high degrees of training and preparation, and, above all, discipline and control. Most of those involved are well aware of their strengths and limitations in the face of clear dangers. Findings of extensive research in climbers suggest that the individuals do not want to 
put their lives in danger by going beyond personal capabilities. (Pain \& Pain, 2005:

The major problems with this risk-taking approach are fourfold. Firstly, a focus on risk has meant that other aspects of the experience such as positive health benefits (Brymer \& Schweitzer, 2012; Brymer \& Oades, 2009; Willig, 2008) and development of a positive relationship with nature (Brymer, Downey, \& Gray, 2009; Brymer \& Gray, 2009), have been largely ignored. Secondly, theory driven perspectives do not seem to reflect the livedexperiences of participants (Brymer \& Oades, 2009; Brymer \& Schweitzer, 2012; Willig, 2008). Thirdly, research reveals characteristics and statistics that do not seem to fit with this traditional assumption about risk (Celsi, Rose, \& Leigh, 1993; Soreide, Ellingsen, \& Knutson, 2007; Storry, 2003). For example, Storry (2003) found that in the UK the death rate for climbers was 1:4000 which compares favorably against motor cycle riding where the death rate is 1:500. Soreide et al. (2007) undertook an analysis of 20850 BASE-jumps in Norway over 11 years and found that the death rate was 1:2317 and while the injury rate was high they were in the main linked to sprains and bruises. Studies have also indicated that extreme sport participants are not inclined to be reckless. For example, the study by Celsi et al. (1993) referred to numerous examples of well-respected extreme sport participants who considered that they participated well within their personal capabilities. The preference was to leave participation for another day if they felt that the limits of their capabilities were being extended. Pain and Pain (2005) observed that athletes expend considerable time and effort to develop high level skills and a deep understanding of their particular activity and also undertake extensive planning. They deliberately become very familiar with all the variables including the environment, their equipment, and the weather.

Finally, research is finding that participation in extreme sports might have positive psychological and emotional outcomes such as the development of courage and humility and 
the transformational benefits of fear (Brymer \& Oades, 2009; Brymer \& Schweitzer, 2012; Willig, 2008). With participation increasing so rapidly it is arguably essential that we gain a better understanding of what constitutes an extreme sport, what motivations and meanings are involved and how we can best determine the benefits and costs of participation. This article presents one element of the extreme sport experience that points to an understanding of motivations for involvement based on findings from a larger hermeneutic phenomenological account of the extreme sport experience, the search for freedom.

\section{Extreme Sports and Freedom}

A review of the sport psychology literature reveals that studies have rarely examined freedom from a phenomenological perspective despite the notion being a valuable and critical discussion point in sport psychology (Nesti, 2011). Previous research on extreme sports has proffered the idea that freedom motivates participation (Welser, 1997). Advertisers and marketers who have exploited the notion of freedom in sport have often juxtaposed adventure sports, such as climbing, with a product such as brands of energy drink (e.g., Mountain Dew and Red Bull) and even cigarette smoking (Pollay, 2001; Welser, 1997). At the same time, freedom has also been juxtaposed with the constraints of modern society (Lambton, 2000; Welser, 1997), with the theme that participants in certain sports are able to avoid the constraints of social domination and social control.

As an example of the juxtaposition, advertisers created the Marlboro man to appeal to the young male based on a perception of freedom. As suggested by Pollay (2001):

He is totally and autonomously free - usually alone with no parents, no older brothers, no foreman, no bullies, indeed no one at all whose authority must be respected. It seems no accident that there is no sheriff in Marlboro Country. (p. 
Here, the advertisers appear to be linking their product to a sense of self where the individual appears disengaged from all around him as Pollay notes "it seems no accident that there is no sheriff in Marlboro country," (p.72) the self is privileged above all else. In this instance, extreme sports have been used to reflect a particular stance.

Previous research has found that extreme sports participants consider that participation in their chosen activity reflects a desire to free themselves from the rules, restrictions and limitations enforced in the everyday social world (Yakutchik, 1995). Bower (1995) built on this concept in suggesting that extreme sport participation was about "looking for a sense of excitement and challenge that is missing from their everyday lives" (p. 21) and by extension extreme sports participants are freeing their very selves from boredom and routine. Extreme sports participants consider that their chosen activity allows freedom from normal life independent of all social and economic constraints (Celsi et al., 1993; Shoham, Rose and Kahle, 2000). Ostensibly, Midol and Broyer (1995) determined that extreme sports provide an "aesthetic liberation of life" (Midol \& Broyer, 1995, p. 209) that transgresses both traditional sporting rules and regulations imposed by traditional societal norms. Athletes engaging in extreme sports associate the experience with a sense of self unconstrained by social norms.

In summary, studies have posited that extreme sport participants attempt to use their sport as a way of freeing themselves from socio-cultural constraints. Researchers have most often focused on sociological rather than psychological frameworks, relied on anecdotal data or investigations, or examined a specific sport such as rock climbing or surfing from a cultural perspective (Booth, 2005; Wheaton, 2007; Winstead, 1996). Marketers have also presented extreme sports as a search for freedom in order to exploit a concept and project an image on extreme sports. 
The aim of this paper is to explore the theme of freedom in the extreme sport context based upon the direct experience of extreme sports participants. This study has adopted a hermeneutic phenomenological approach to explicate the experience of freedom with a view to gaining a better understanding of the meaning of freedom within the context of sport.

\section{Phenomenology and Freedom}

Freedom has been central in the writing of phenomenologist's such as Heidegger and Merleau-Ponty (Nicols, 2000). Heidegger (1996) posited a positive freedom in that he considered freedom to be more than just the absence of constraints, a construct he called freedom-from. In Heidegger's terms, freedom is about being free to choose to live authentically. Nicols (2000) wrote that freedom defines "Dasein's authentic potentiality for being, a potentiality which reveals the being of beings as they are 'in themselves', including both innerworldly beings and Dasein itself' (p. 3). Freedom entails being free from the social "they" of everyday life and accepting the reality of the abyss (nothingness), the acceptance of the presence of anxiety and of being open to confront one's own death (Breivik, 2011).

From a phenomenological perspective, freedom is more than being free from sociocultural constraints and doing what one wants. Freedom involves the exercise of choice based on a primordial freedom and the acceptance of an ever present anxiety. Heidegger (1996) determined that freedom was only possible if primordial freedom, otherwise defined as the connection to or "revealing of historically 'grounded' truth" (Nichols, 2000, p. 14) was first experienced. Without such an intimate connection, freedom becomes a forced construct which is dangerous and might result in enslavement (Nichols, 2000). From a phenomenological point of view, extreme sports can only to be considered in terms of freedom if they enable an experience of truth as primordial freedom. In turn, this leads to a positive freedom as choice and a release of anxiety and fear. 
Ricoeur (1966), in common with existential schools of philosophy argued that the structure of human freedom is freedom as choice, freedom as movement and freedom as consent. Thus, those following the existential phenomenological tradition also perceive freedom in terms of freedom as action of some kind. Ricoeur considered action in terms of a decision, a movement that confirms my freedom and importantly also a consent to carry out such a freedom. Ricoeur posited that freedom entails awareness that a person is free to choose their own destiny. However fear, specifically fear of death but more crucially fear of being an individual, prevents the realization of each person's freedom.

In summary, a phenomenological exploration of the meaning of freedom suggests that freedom has multiple characteristics. Freedom is simultaneously 1) a release from or movement away from undesirable constraints such as societal or cultural mores; 2) the application of choice and responsibility which reflects existential anxiety and 3) movement and action.

\section{Hermeneutic phenomenology in research}

This paper, drawing upon a larger study of extreme sport experience (Brymer, 2005) adopts a hermeneutic phenomenological approach. The focus of the current findings is upon the search for freedom. Six key themes around the experience of freedom in an extreme sports context are explicated: freedom from constraints; freedom as movement; freedom as letting go of the need for control; freedom as the release from fear; freedom as choice and personal responsibility; and freedom as being at one.

While phenomenological research seeks to illuminate the essence of an experience, hermeneutic phenomenology, accepts that lived experiences are always made sense of, that is, sense making is both intentional involving "consciousness-of" and interpretative. Interpretation occurs through language and therefore participant accounts reflect the ways that individual participants make sense of their experience (Willis, 2001). In contrast to a 
cognitive paradigm which is based upon dualistic conceptions of human experience, phenomenology challenges dualism as it is based upon notions of consciousness being co constitutional. The challenge to dualism, which underpins much of science, is consistent with an ecological approach which values emergent phenomena such as the experience of freedom. In practice this means that the researcher must engage in a rigorous and iterative process of explication which involves a deep understanding of the lived experience as well as his or her role in making sense of such experiences (Smith, Flowers, \& Larkin, 2009).

The issue of rigour is always important when undertaking qualitative research. Traditionally, rigour has been achieved through established natural scientific criteria. Some schools of qualitative research have attempted to apply such criteria to qualitative research, and have utilised such criteria as inter-rate reliability and triangulation. However, others have critiqued the role of blindly following such criteria as following such criteria does not guarantee good quality research (Sparkes \& Smith 2009). Criteria emanating from natural scientific research are often problematic in relation to hermeneutic phenomenology due to philosophical inconsistencies. As argued by De Witt and Phoeg (2006), rigour needs to be achieved through a range of processes which might include such considerations as balanced integration, openness, concreteness, resonance, and actualization. Balanced integration in the current study refers to the intertwining of philosophical concepts which draw upon phenomenology and the reported experiences of extreme sports participants. Openness is understood as being related to a systematic, explicit process of accounting for the multiple decisions which are made over the course of the study process. In the current study, these decisions are made explicit in the following sections. Concreteness, within this paradigm, relates to usefulness of findings. While concreteness is not a focus of the current study, the findings never the less, contribute to an understanding of the phenomenon. Resonance 
encompasses the experiential effect of reading study findings upon the reader. This process was followed in the current study by the use of member checks as outlined below.

The relationship between quotes, meaning and the role of language is complex. Hermeneutic phenomenological researchers posit that, although language and explicit accounts are a crucial tool in understanding experience, immediate experience is always prereflective and thus not wholly determined, or captured by language (Ajjawi \& Higgs, 2007). Therefore, the hermeneutic phenomenological approach aims to penetrate deeper, beyond the reflective interpretation of an event, to get as close to the phenomenon as possible. This iterative process includes elements that might elude language or be underemphasized in explicit accounts because language is not sufficient to communicate abstract dimensions of experience (van Manen, 1997b). As Willis (2001) pointed out:

When speech, language and thought patterns generated from experiences in the world are used, they always involve an interpretive process: but the aim here is to try to disclose the most naïve and basic interpretation that is already there but as yet is unelaborated in the life world experience, a phenomenological hermeneutic. (p. 7)

The hermeneutic approach is particularly appropriate when attempting to assemble a phenomenological account of other people's lived experiences, especially when this experience is being studied for the first time, when a particular topic requires a fresh perspective or when the experience is difficult to access (Cohen, Kahn, \& Steeves, 2000). The hermeneutic phenomenological approach is to carefully gather and analyse first-hand accounts of an experience from those who have had the experience rather than projecting the analysts' own biases or pre-conceived understandings of what is occurring. Hermeneutic phenomenology also allows the researcher to draw upon additional knowledge from the work of poets, authors, artists, and cinematographers in addition to participant interviews in the 
desire to more fully explicate the 'immediate common experience in order to conduct a structural analysis of what is common, most familiar, most-evident to us' (Willis, 2001, p. 19). In practice this process requires that the researcher be open to what informants report during the data gathering and explication process. The researcher is required to suspend or 'bracket' previous knowledge or subjective understandings about the experience.

In the course of the current study into the extreme sport experience, freedom emerged as one of several significant themes. Other themes comprised: transformation, becoming what you are, coming home, and evoking the ineffable (Brymer 2005). However, these themes are outside the scope of the current paper with its focus upon the key theme of freedom.

\section{Method}

\section{Participants}

Following ethics approval, form an Australian university ethics committee, interviews were undertaken with 15 extreme sport participants (ten men and five women aged 30 to 70 years) from Europe, Australia, and North America. Extreme sports included BASE jumping $(n=4)$, big wave surfing $(n=2)$, extreme skiing $(n=2)$, waterfall kayaking $(n=2)$, extreme mountaineering $(n=3)$ and solo rope-free climbing $(n=2)$. Extreme sport participants were chosen based on the following inclusion criteria: (a) they participated in activities that we classified as extreme sports; and (b) they were older than the population traditionally considered primary participants. This second point was vital because there is a considerable body of research that maintains young people (16-25 years) search for risk-taking opportunities in diverse activities, which might include extreme sports (Janssen, Dostaler, Boyce, \& Pickett, 2007; Jonah, 1986; Sharland, 2006) and (c) they were able and willing to reflect on and explore their own extreme sport experience. 


\section{The Interviews}

An hermeneutic phenomenological approach was adopted (Allen-Collinson, 2009; Brymer, 2010; Brymer \& Gray, 2010; Brymer \& Schweitzer, 2012) following recommendations by van Manen (1997a, 1997b). The phenomenological approach requires the investigator to enter the project with an open mind (Giorgi, 1997). Interviews comprised focused conversations with extreme sport participants, conducted face-to-face or by phone over a five year period. One question guided the interview process: "What is your experience of your activity?" Follow-on prompts were posed to more deeply explore aspects of the participant's experience.

\section{Explication of Interview Data}

The explication involved five steps. In the first step, each interview was recorded, transcribed and listened to carefully in order to gain a sense of the respondent's experience as a whole. The second step comprised a thematic analysis during which transcripts were read with a view to identifying themes. Potential themes were questioned, challenged and assessed for their relevance and accuracy. At the same time, the researchers attempted to identify and bracket presuppositions to not bias the explication. Interesting phrases and non-verbal considerations were noted. Thirdly, the notes were reconsidered in terms of potential underlying thematic phrases for meaning (DeMares, 1998; Moustakas, 1994). Fourthly, thematic ideas that emerged from this careful examination were clustered and further defined. Second order themes were considered against the original transcripts to ensure the accuracy of interpretations. For example, the authors made sure that the analysis did not group together concepts that participants used to make fine distinctions that they found important. Fifthly, the entire process of moving between the parts and the whole was repeated recursively with the aim of reaching a point of saturation in understanding the topic of the study within the 
extreme sport experience. The resultant themes were presented to the participants for feedback.

\section{Results}

The following section reports on one aspect of a larger hermeneutic study, the search for freedom. The interview data revealed a deep and felt sense of deliberate and active freedom that seems to lie beyond the assumption of being free from cultural or societal constraints. From a phenomenological perspective human's live in relation to their object of consciousness. In exploring the theme of freedom we have divided this relationship into the following themes: freedom from constraints; freedom as movement; freedom as letting go of the need for control; freedom as the release of fear; freedom as choice and personal responsibility; and freedom as being at one.

\section{Freedom from Constraints}

Extreme sports participants reported a number of ways in which freedom reflected a desire to be free of constraints. Freedom from constraints was considered at once sociocultural, physical, emotional, and mental as epitomized by the following reflections from an extreme skier:

You feel so free out there, you don't worry about anything, you don't think about the bills you've got to pay or your life problems, you're just kind of free of thought. That's kind of what makes it all worthwhile, just for that whatever, five minutes of freedom. (Participant 1, female, mid 30s)

Freedom emerged as a deliberate attempt to find release from the constraints of normal daily existence. For example, this participant described a sense of release from the mundane and the demands of living within a community to a new found sense of liberation. The sense of liberation was highly valued even if for only limited time. Underpinning her experience is the attraction of surrender to the experience. This is beyond the idea of 
relaxation as the participant speaks about active engagement with the experience in the here and now.

I call it defying gravity and I define gravity as all the things that pull you down in life you know everyday living just dealing with [...] with everyday life is often a hassle where as BASE jumping is very free its very peaceful. (Participant 2, female, mid 30s)

Similarly, this participant experienced freedom in terms of defying the laws of physics such as gravity, which she considered metaphorically in terms of "pulling you down". In contrast, her engagement in extreme sport provides both an expression of freedom as well as freedom from the constraints referred to previously.

\section{Freedom as Movement}

Participants described how extreme sports provide an experience of being free to move. Perhaps most exemplified by extreme climbers who literally climb free of the traditional climbing paraphernalia. A participant who was a free-solo climber expressed this in terms not only of being free from constraints but also the importance of movement:

So I was stuck on my own usually in mid week here in Wales and that's when I started solo climbing. So I really started from necessity really plus it appealed to me but I found out that I had a great delight in doing it I liked the feeling of the freedom of it being up there you know with no paraphernalia no slings or things or ropes and you just move freely. (Participant 3, male late 60s)

For this participant, freedom was experienced as being with oneself and at the same time without constraint. For this informant the idea of situating himself in a context where he confronts danger and exercising the choice of confronting such danger without paraphernalia contributes to a special sense of freedom. He expanded on this in the following clarification: “... that sort of freedom was really freedom of movement as 
opposed to what you'd think as freedom being in the mountains and the wide open spaces" (Participant 3, male late 60s). That is, his capacity to move within that space which is precarious based on the juxtaposition of safety and of threat to safety provides a special kind of freedom. This leads to the existential dimension of the degree to which humans exercise choice.

\section{Freedom as Letting Go of the Need for Control}

Participants in extreme sports have expressed the desire to seek a sense of freedom through a letting go of control. That is part of the experience is characterized by the sensation of having no control. This is counter intuitive to the more common experiences of being in control. The experience is described as one where participants undertake a great deal of effort ensuring that they are prepared psychologically, that their equipment is appropriate and that they understand the environment, but in the end they accept that they have little control during the activity. For example, an extreme kayaker recognized that he did everything that he could to control the outcome but at the same time he also recognized that the only way to be fully in control was not to undertake his activity and walk around the waterfall instead of paddling over the waterfall. Essentially, he recognized that despite his best efforts he could not control nature:

Yeah very important controlling what is happening there, everything from the equipment I use right the way through to ... well I'll exercise as much control as I possibly can with the exception of walking around the edge of the waterfall to get to the bottom. (Participant 4, male mid 30s)

The experience of not being in control at a certain point are not the same as being out of control but more about accepting that certain elements are not within a participant's control. The non-control or the unplanned, unscripted, or uncertain element of the experience is all important. That is participants did not wish to be out of control but more accepting that 
some experiences have uncertain outcomes. Participants reported that they have to know their own abilities, what aspects of the activity are controllable as well as accept that some aspects of the activity are uncontrollable or uncertain. For an extreme skier interviewed for this study the feeling of freedom seemed to be more about straddling the edge of control.

Well like I said when I'm skiing at my very best I feel like I'm on the very edge of complete destruction. I look totally in control [but] if you look at a downhill skier in slow motion their skis are just wobbling all over the place but they're still hanging on that's when I'm skiing my best. Like how that looks is how I feel. (Participant 5, female mid 30s)

An extreme kayaker expressed the feeling of letting go of control as: not a feeling of accomplishment but this feeling of freedom more than anything else and particularly that I had bitten off more than I could chew almost as soon as I'd done it. I can remember that so often in life that feeling that I really shouldn't have done this and it still happens all the time now when I run waterfalls on the way down I'm thinking I really shouldn't have done this, I really didn't need to learn this lesson. (Participant 4, male mid 30s)

To clarify this point for Participant 4 the experience was not about just seeing what happens but a managed non-control. Thus, the aspect of control seems to be one of controlling what is controllable and accepting, understanding and perhaps even letting go or surrendering to the experience. Participant 4 described the experience of kayaking including the spins and knowledge of the river and the challenges of the process as follows:

floating down there thinking what is the waterfall doing with me I feel a little bit out of control just because I'm not doing anything the water is taking me really so it's not to see what happens but just certain maybe five percent of me feels that I don't actually know what is going to happen. (Participant 4, male mid 30s) 
The participant thus describes the paradox of both being in control and not in control at the same time. The kayaker noted that control is no longer possible as soon as he leaves the last eddy (quiet water). He described an intense feeling of the reality of non-control over his own death.

I'm sitting at the top and the final goodbye is said and the last person walks away from the top of the fall, it feels like my only job is to get out of the bottom of the waterfall alive. The only thing I have to do is to survive and that's quite an amazing turning point because that's the last point at which I could say no. If I am going to die that was the last time that I had any control over it and it's a very very strange feeling to break out of that eddy. (Participant 4, male mid 30s)

The respondent thus revealed the essential element of his experience which is to exist between being in control and letting go of control and that is the very juxtaposition of control and loss of control which he experienced as freedom within the here and now. The scent of danger is experienced as contributing to the experience as opposed to detracting from the experience.

In contrast to the everyday desire to maintain or gain control over the environment and the assumption that control is necessary participants in this study clearly regard control as only part of the experience. At some stage in the experience participants describe accepting that control is not longer possible and that the moments when control is not possible are defining moments in the experience.

\section{Freedom as the release of fear}

Freedom was revealed as a complex construct, in part deriving value from itself and in part from the experience of freedom as distinct from alternative experiences, In this case fear. This is evident in a respondent who expressed his experience thus: "the trick I think is to be able to control the fears and then if you've got full control over your fear then you don't 
feel hyped up with adrenalin but that's why you are feeling relaxed" (Participant 6, male early 40s).

Clearly the respondent attained a sense of control which he linked to a more pleasant experience, that is feeling relaxed. Another respondent described his experience as follows:

You know we learn all these complex systems of fear as we get older and that's part of society's rules. The real reward of doing something like BASE jumping, which initially you fear as it's scary, the real reward, personal reward is overcoming that fear, going right through it and turning it into elation. Turning it into this incredibly exhilarating experience this absolute celebration of living. (Participant 6, male mid 40s)

Again, the respondent reveals a capacity to experience fear that portrays his own capacity to "take it on" as he described "going through it" and "turning it into elation" which he compares to celebration. His participation in extreme sport thus rendered a potentially frightening and destructive human emotion into an experience of exhilaration. In this instance, freedom from the effects of fear seems to be also about going through fear and into elation.

While participants speak about overcoming and managing fear, this is less about a deliberate attempt to control fear and more about a realization that fear can be transcended. This is suggested by participant 3, a solo climber, who contended that as the moves required to climb at any level are the same the only difference to soloing at high levels is the ability to move despite the fear. Thus, the challenge was an inner challenge and moving through the fear described as a feeling of well-being. For Participant 3, taking positive action counteracts negativity:

The greatest fear comes the night before when my mind is in overdrive but I seem to be very calm when it actually comes to do it because there seems to be like an 
inner turmoil where one part of my mind says don't do this it's crazy you might kill yourself and the other part says no I'm gonna do it. The other side keeps me calm because subconsciously you probably realize that's the way you are gonna do it as safely as possible. (Participant 3 , male late 60s)

The person revealed his own ambivalence which he described in terms of a part of himself thinking what he was going to do is crazy and another part which argued for participating in the experience. He determined that as such participation is associated with feeling alive and as a result needs to be undertaken while engaging in safe practices. $\mathrm{He}$ thus resolves an intrinsic issue which arises when balancing the power of the experience and the real dangers involved. Fear is apparent until the decision to participate when calm takes over.

\section{Freedom as being at one}

A number of participants described a sense of freedom in terms of peace or being at one as participants were immersed in the natural environment. One BASE jumper expressed this theme well as he described his relationship with the natural environment:

on a BASE jump off a beautiful cliff there are no people and there is no wind because you're not going to jump if there is wind. So it's very very still, very quiet and so you can take a few moments to become one with the environment. That's very peaceful like you sometimes sit at the top of cliffs for ages waiting for the right conditions, waiting for the wind to drop and those times there's nothing else to do but be there and be with yourself and be with what you're about to do. You've taken yourself out of your everyday existence where peace is quite hard to find and put yourself in an environment where it's easy to be peaceful. (Participant 8 , female late $30 \mathrm{~s})$ 
The respondent thus described an acute sense of experiencing the natural world both subtly and intensively as she waits for the perfect conditions to engage in an extreme sport activity. The participant also revealed the degree to which physical freedom in extreme sports is in a different conscious plain as she contrasted her experience with what she terms everyday existence. She is thus able to experience a state of being which is unique to her participation in her chosen activity.

Another participant related; "relaxation is part of why you do it because you are obviously hitting some sort of plane that you can't normally hit" (Participant 9, male late 30s). Freedom, then, has become more than an active and deliberate attempt to un-knot the socio-cultural restraints but also an active and deliberate attempt to experience physical liberation. Further, the suggestion seems to be more than just the ability to physically move but also a kinesthetic realization of being free. Participant 8 likened this freedom to freedom of the mind akin to meditation. This focus should not be confused with tunnel vision or a narrow state of focus, merely that the focus required frees the mind from unnecessary mental activity. As expressed by the following participant:

The closer you can come to being at one with the environment the more peaceful it is. I suppose when you think about it, it has to come from the inside, it's how we choose to look at it. So I suppose how peaceful each jump is is determined by how well I do at getting into that state. (Participant 8, female late 30s)

Again, the respondent iterates a sense of freedom derived from being at peace with her environment which in turn is associated with her chosen sport. This respondent's comment also suggest the query, is she choosing a sport or a state of mind and a way of getting into that state of mind?

\section{Freedom as choice and personal responsibility}


Almost all participants described an experience of freedom to choose in relation to their participation in extreme sports. This theme will deal more specifically with the experience of freedom in the present tense. The first example, drawn from a BASE jumper exemplifies personal responsibility:

I would have to take TOTAL personal responsibility for my actions too. There was just me, my physical and mental abilities my training, and "a piece of nylon and string" to save my life. This satisfied another one of my dreams to be able to exist outside the confines, rules, protection and brain numbing existence that typifies modern society. (Participant 6, male early 40s)

This participant reflects deeply on the degree to which he takes responsibility in his immediate existence. As he reported on his experience, he referred to the degree to which he lived his life hanging on a thread in his reference to "nylon and string". The participant's experience suggested that he existed within a limbo between living a vibrant life and the immediacy of the potential of the abyss or non-existence. While he trained to exist within this precarious place, he nevertheless maintained a sense of the precarious nature of his existence.

This participant, who works within an emergency medical setting, discussed at great length the degree to which humans live with little awareness of the precariousness of their lives. The above quote revealed the importance he attached to both responsibility and a capacity to dream. Life is not bounded by the constraints of normative experience but rather his involvement in extreme sports is an opportunity to dream and experience outside the confines of what he termed modern society. Freedom was perceived to be more than solely an active and deliberate attempt to be free from the socio-cultural constraints or physically free but also a freedom to make a decision and accept responsibility for his own actions and his own physical destiny. 
A kayaker described the importance of accepting the responsibility for his own physical life expressed as "my responsibility is just for my life" (Participant 4, male mid 30s); but on deeper reflection, he expressed a freedom associated with the physical aspect of his chosen activity and the environment:

The thought that my life is in someone else's hand would worry me quite a lot but having it in my hands doesn't really feel very special. I think that what is coming out on reflection is it's very much a way of thinking rather than a sport.

(Participant 4, male mid 30s)

Here the participant is describing the experience of being engaged in extreme sports not only in terms of the sport itself but as a way of being-in-the-world. His involvement in kayaking is experienced as a metaphor in which he is free to lead his life in response to his own desires and actions rather than restricting his responses to external constraints. These experiences are expanded upon in the quote following: He stated:

If I'd been a kid who was always jumping off things to try and fly and ended up in paragliding I think I'd be the same person in paragliding but I just love water I don't know why I love water but I've been drawn to water. (Participant 4, male mid 30s)

The participant again draws further attention to the degree to which he achieved his own individuality through his decision making which involved water and the consequences thereof. This participant represented a recurring theme that is the activities which people engage in are not random but reflect a potential deep connection between each person and their particular activity, not unlike people in ancient communities who had an affinity for particular animal totems.

Another BASE jumper expressed a similar opinion in that the active and deliberate acceptance of responsibility for her own destiny was recognized as a total freedom but more 
than that this freedom came from letting go of the need to attach experiences to external answers and an acceptance of her own inner experiences:

People call it selfish and it probably is the ultimate selfishness because it's just you and nobody else can help you. There's no-one else to turn to so you're totally responsible and there's a lot of freedom in that knowledge because you're not looking outside of you for the answers. They can only come from inside ... and that to me is freedom. (Participant 8 , female late 30s)

The participant, who is a mother, accepted that she was not fitting into society's expectations of putting her children first, equated her experience with what she termed ultimate selfishness which she experienced as responsibility for herself and accepting the consequences of her actions. Extreme sport participation is experienced as an ultimate way of being with oneself. Her reference "there is no-one else to turn to" contrasts with so much human activity which occurs within the context of community. Similar to a previous respondent, this respondent seeks out experiences leading to the sense of individual responsibility and individual consequences involved in the activity despite the realization of the potential downside.

It's linked to that concept of commitment and taking responsibility in doing something that the vast majority of people would never contemplate. They would just look at it and go that's nuts ... but the powerful thing about it is that as I mentioned to you before its totally up to you no one can help you and you are taking responsibility for your own life totally. It's your decision to jump or not jump. Like everyone else around you makes their own decision based on their skill and experience and how they're feeling that day. (Participant 8 , female late 30s) Again the respondent reiterates the themes of commitment, responsibility, freedom to make one's own choices and living outside normative community decision-making. It 
is in this sense that the respondent is able to achieve a sense of individuality in which choice and responsibility emerge as significant.

In the same quote, she continued to define freedom as a physical expression directly linked to her chosen activity within her chosen environment. Once again, this quote emphasizes self-responsibility and freedom to choose.

The sensation is a great freedom like you're defying Einstein's law and there's a physical sensation that feels very free. We did one jump at night and that was another time where you don't have a filter for that, you don't have anything to compare it to you, imagine just jumping into blackness. So the only thing you got to rely on is yourself. (Participant 8 , female late 30s)

The experience of self-responsibility then related to being responsible for one's own life in terms of the 'life-death' relationship as previously noted and in terms of being-andaccepting-personal-responsibility. In the words of Participant 6, male, mid 40s:

You know to accept and handle that responsibility and say yes I will I will find my own meaningfulness and my own fulfillment and you know everybody gets an opportunity but not that many people actually take up the mantle.

Each of the respondents quoted above give voice to the motivation which underlies their activities that is a sense of empowerment to redeem self-responsibility and the sense of not knowing what they are letting themselves in for. These expressions provide support for one of the significant aspects of freedom as exemplified in extreme sports.

\section{Discussion}

The current findings point to the ways in which humans seek freedom through their participation in extreme sports. The themes explicated were: freedom from constraints, freedom as letting go of the need for control, freedom as the release of fear, freedom as being at one and freedom as choice and personal responsibility. That is participation in extreme 
sports reveals the capacity of humans to experience a sense of liberation. This has to do with freedom of the self to make choices, to take responsibility, and at a more fundamental level to experience life as authentically human. That is, the person is open to experience self in relation to nature without the boundedness which characterizes everyday living within a civil society. In contrast to the predictability which characterizes everyday life, participation in extreme sport challenges the very notion of predictability by living at the extreme.

Participants revealed a consciousness of choosing a way of being-in-the-world in which predictability was subjugated in preference to letting go of control. There is also a paradox to participants' experience in that they develop skills to engage in activities "at the extreme" and develop the skill and flexibility to experience some degree of control and mastery of the techniques which enable them to engage in the activities. There is an appreciation that the natural world is much more powerful than the self in the sense that the participant's experience is awesome in the literal sense of being filled with awe in relation to the power of the natural world. Participants reveal a capacity to work hard to obtain skills and knowledge to enable control and participate effectively while still knowing that in the end control is not possible. In the words of the mountaineer Eric Perlman 'we are designed to experiment or die' (Perlman cited in Dowell et al., 1999, p. 30). Gonzales (2003) observed similar experiences and described them as a release of the desire to predict and anticipate and the ability to watch, be clear and calm, and act decisively to stimuli.

Extreme sports have been associated with a desire to recapture life in its immediacy and with pushing personal boundaries. The latter refers to living life where danger is confronted through recourse to skill and an attitude of courage. The climber Participant 3, who spoke about having the skill to move through fear exemplifies this in this study. From a phenomenological perspective, fear is confronted and transcended (Brymer and Schweitzer, 2013). There are arguments that socialization might have unanticipated consequences by 
desensitizing aspects of what it means to be person. In contrast, participation in extreme sports removes the person from the social constraints or the "they-self" as outlined by Heidegger where a participant is searching their soul to explore personal limitations. By deliberately searching for activities that perhaps, human beings 'should' not be doing, a participant gains freedom from inhibitions and a realization of personal potential. In this study, Participant 1 succinctly illustrates the search for meaningfulness. That participation in extreme sports provides participants with an experience of living on the edge between the mundane and the potentially transcendent (Brymer \& Neilson, 2012).

In summary, an explication of the extreme sport experience reveals freedom from socio-cultural control. On a closer inspection of this type of freedom, it would seem that the experience is also a freedom to be responsible for one's own destiny. That is the experience of freedom is reportedly both a movement away from external constraints or being-free-from and a movement towards or being-free-to. Beyond the traditional notion of extreme sports, being about a socio-cultural freedom is a freedom that is at once physical, emotional, and mental. Participants speak about being physically free to move, mentally free from unwanted noise and free from the chains of fear, often considered a total relaxation. A freedom that is seemingly about letting go and of or finally surrendering the need to control and experiencing the experience as it is.

There is also an evolutionary perspective to extreme sports which questions the traditional perspective that extreme sports and the danger which goes with such activities are essentially a deviant desire aligned with thrill-seeking. We would suggest that from an evolutionary perspective the degree to which humans consistently comply with social norms and health and safety constraints could itself be deviant from the perspective of people who in times past would have conducted much of their lives within a danger beckoning environment. Escaping such dangers might constitute an ongoing obsession for safety- 
seeking in contrast to the participants in this research project. Extreme sport participants may be more akin to our forebears and their expression of self and the ability, however fleetingly, to experience themselves as authentic.

The experience of freedom in participants in extreme sports in this study seems to lift the mist of everyday living to enable the extreme sports participant to gain a sense of clarity which for some, included a deep sense of personal meaning which was not socially constrained. The societal emphasis, whether dominant or sub-cultural, on integration of people into societal norms, loses its power. Perhaps there is dissatisfaction with norms but not explicitly to move away from something that is inherently bad but because they have found something of greater personal value. Extreme sports participants give up the trappings of comfort and security for a life of personal meaning and challenge. Thus life becomes a matter of choice, as opposed to necessity as determined by society (Heidegger, 1996), as a person accesses that inner space of being and moves towards authenticity.

\section{Conclusion}

An essential piece of the extreme sport jigsaw of experience is freedom, a freedom that is at once movement away from unwanted constraints and movement towards desirable states. From a phenomenological perspective, freedom can be conceived as 1) freedom from, which suggests a liberation from unwanted societal constraints or cultural mores, 2) freedom as, which was previously defined as movement and action. Each of these dimensions of freedom is reflected in the explication of the extreme sport experience. Freedom was described as a freedom from social, cultural, and other elements that constrain a participant's life. However, more than this the freedom described is also a freedom where participants describe being free to accept personal responsibility. In this form, freedom is mental and physical encompassing the notions of desire and movement. However, another type of freedom emerges in the explication of extreme sport participants involved in the current 
study, that is, a sense of freedom which equates to freedom from thought and fear and that explores a novel dimension of consciousness. A consciousness that might indicate the extreme sport experience touches realms of human existence beyond that experienced in every-day-living. That is the participants in the current study reveal a lived-world experience of freedom expressed in the freedom to let go, surrendering the need to control and experiencing the experience in and of itself.

\section{References}

Ajjawi, R., \& Higgs, J. (2007). Using hermeneutic phenomenology to investigate how experienced practitioners learn to communicate clinical reasoning. The Qualitative Report, 12(4), 612-638.

Allen-Collinson, J. (2009). Sport embodiment: Sports studies and the (continuing) promise of phenomenology. Qualitative Research in Sport and Exercise, 1, 279-296. doi: $10.1080 / 19398440903192340$

American Sports Data. (2002). "Generation Y" drives increasingly popular "extreme" sports. Sector Analysis Report, Retrieved from http://www.americansportsdata.com/prextremeactionsports.asp.

Booth, D. (2005). Paradoxes of material culture: The political economy of surfing. In J. Nauright, \& K. S. Schimwill (Eds.), The political economy of sport (pp. 104-125). Basingstoke: Palgrave MacMillan.

Bower, J. (1995). Going over the top (extreme sports). Women's Sport and Fitness, 17(7), 2124. Retrieved from http:/go.galegroup.com.ezp01.library.qut.edu.au/ps/i.do?id=GALE\%7CA17639283\& $\mathrm{v}=2.1 \& \mathrm{u}=\mathrm{qut} \& \mathrm{it}=\mathrm{r} \& \mathrm{p}=\mathrm{HRCA} \& \mathrm{sw}=\mathrm{w}$ 
Breivik, G. (2011). Dangerous play with the elements: Towards a phenomenology of risk sports. Sport, Ethics and Philosophy, 5, 314-330. doi:

$10.1080 / 17511321.2011 .602585$

Brymer, E. (2002, October 25). Extreme sports: Theorising participation - a challenge for phenomenology. Paper presented at the ORIC research symposium, University of Technology, Sydney.

Brymer, E. (2005). Extreme dude: A phenomenological exploration into the extreme sport experience. Doctoral Dissertation, University of Wollongong, Wollongong. Retrieved from http://ro.uow.edu.au/theses/379.

Brymer, E., Downey, G., \& Gray, T. (2009). Extreme sports as a precursor to environmental sustainability. Journal of Sport and Tourism, 14, 1-12. doi:

$10.1080 / 14775080902965223$

Brymer, E. (Author), \& Nielson, J. (Producer) (2012). Transcendence. [DVD] . Southern Underground Productions, New Zealand.

Brymer, E., \& Oades, L. (2009). Extreme Sports: A positive transformation in courage and humility. Journal of Humanistic Psychology, 49, 114-126. Doi:

$10.1177 / 0022167808326199$

Brymer, E. (2010). Risk and Extreme Sports: A phenomenological perspective. Annals of Leisure Research, 13, 218-239.

Brymer, E., \& Gray, T. (2010). Dancing with nature: Rhythm and harmony in extreme sport participation. Adventure Education, \& Outdoor Learning, 9, 135-149. doi: $10.1080 / 14729670903116912$

Brymer, E., \& Schweitzer, R. (2012). Extreme sports are good for your health: A phenomenological understanding of fear and anxiety in extreme sport. Journal of Health Psychology. doi: 10.1177/1359105312446770. 
Celsi, R. L., Rose, R. L., \& Leigh, T. W. (1993). An exploration of high-risk leisure consumption through skydiving. Journal of Consumer Research, 20, 1-23. doi: $10.1086 / 209330$

Cohen, M. Z., Kahn, D. L., \& Steeves, R. H. (2000). Hermeneutic phenomenological research: a practical guide for nurse researchers Thousan Oaks: Sage.

Delle Fave, A., Bassi, M., \& Massimini, F. (2003). Quality of experience and risk perception in high-altitude climbing. Journal of Applied Sport Psychology, 15, 82-98. doi: $10.1080 / 10413200390180080$

DeMares, R. (1998). Peak experiences with cetaceans: A phenomenological study. Doctoral Thesis, The Union Institute Graduate College, California, San Francisco.

Dowell, W., Rawe, J., Fulton, G., Krantz, M., Maloney, J., E., M., Woodbury, R. (1999). Life on the edge: Is everyday life too dull? Why else would Americans seek risk as never before? Time, 154(10), 28.

Giorgi, A. (1997). The theory, practice, and evaluation of the phenomenological method as a qualitative research procedure. Journal of Phenomenological Psychology, 28, 235260. doi: $10.1163 / 156916297 X 00103$

Heidegger, M. (1996). Being and Time: A Translation of Sein and Zeit (J. Stambaugh, Trans.). Albany: State University of New York.

Janssen, I., Dostaler, S., Boyce, W. F., \& Pickett, W. (2007). Influence of multiple risk behaviors on physical activity-related injuries in adolescents. Pediatrics, 119(3), e672-e680. doi: 10.1542/peds.2006-0339

Jonah, B. A. (1986). Accident risk and risk-taking behaviour among young drivers. Accident Analysis, \& Prevention, 18, 255-271. doi: 10.1016/0001-4575(86)90041-2

Lambton, D. (2000). Extreme sports flex their muscles. Allsport, September(SB49), 19-22.

Marcuse, H. (1964). One dimensional man. Boston, MA: Beacon Press. 
Midol, N., \& Broyer, G. (1995). Toward an anthropological analysis of new sport cultures: The case of whiz sports in France. Sociology of Sport Journal, 12, 204-212.

Monasterio, E., Mulder, R., Frampton, C., \& Mei-Dan, O. (2012). Personality characteristics of BASE jumpers. Journal of Applied Sport Psychology, 24, 391-400. doi: $10.1080 / 10413200.2012 .666710$

Moustakas, C. E. (1994). Phenomenological research methods. Thousand Oaks, California: Sage.

Nesti, M. (2011). Phenomenology and sports psychology: Back to the things themselves! Sport, Ethics and Philosophy, 5, 285-296. doi: 10.1080/17511321.2011.602582

Nichols, C. M. (2000). Primordial freedom: The authentic truth of dasein in Heidegger's 'Being and Time'. Paper presented at the Thinking Fundamentals, IWM junior visiting fellows conferences, Vienna.

Olivier, S. (2006). Moral dilemmas of participation in dangerous leisure activities. Leisure Studies, 25, 95-109. doi: 10.1080/02614360500284692

Pain, M. T. G., \& Pain, M. A. (2005). Essay: Risk taking in sport. The Lancet, 366(1), S33S34. doi: 10.1016/S0140-6736(05)67838-5

Pizam, A., Reichel, A., \& Uriely, N. (2002). Sensation seeking and tourist behavior. Journal of Hospitality \& Leisure Marketing, 9(3), 17-33. doi: 10.1300/J150v09n03_03

Pollay, R. W. (2001). Export "A" ads are extremely expert, eh? Tobacco Control, 10, 71-74. doi: 10.1136/tc.10.1.71

Puchan, H. (2004). Living 'extreme': Adventure sports, media and commercialisation. Journal of Communication Management, 9, 171-178. doi: 10.1108/13632540510621588

Ricoeur, P. (1966). Freedom and nature: The voluntary and the involuntary (E. V. Kohak, Trans.): Northwestern University Press, Evanston, IL. 
Rinehart, R. (2000). Emerging arriving sports: Alternatives to formal sports. In J. Coakley \& E. Dunning (Eds.), Handbook of sports studies (pp. 501-520). London: Sage.

Self, D. R., Henry, E. D., Findley, C. S., \& Reilly, E. (2007). Thrill seeking: The type T personality and extreme sports. International Journal of Sport Management and Marketing 2, 175 -190.

Sharland, E. (2006). Young people, risk taking and risk making: Some thoughts for social work. The British Journal of Social Work, 36, 247-265. doi: 10.1093/bjsw/bch254

Shoham, A., Rose, G. M., \& Kahle, L. R. (2000). Practitioners of risky sports: A quantitative examination. Journal of Business Research, 47, 237-251. Retrieved from: http://dx.doi.org.ezp01.library.qut.edu.au/10.1016/S0148-2963(98)00093-9

Simon, J. (2002). Taking risks: Extreme sports and the embrace of risk in advanced liberal societies. In T. Baker \& J. Simon (Eds.), Embracing risk: The changing culture of insurance and responsibility (pp. 177-208). Chicago: University of Chicago Press.

Smith, J. A., Flowers, P., \& Larkin, M. (2009). Interpretive phenmomenological analysis: Theory, method and research. London: Sage.

Soreide, K., Ellingsen, C., \& Knutson, V. (2007). How dangerous is BASE jumping? An analysis of adverse events in 20,850 jumps from the Kjerag Massif, Norway. Journal of Trauma-Injury Infection, \& Critical Care, 62, 1113-1117. doi:

10.1097/01.ta.0000239815.73858.88

Sparkes, A.C., \& Smith, B. (2009). Judging the quality of qualitative inquiry: Criteriology and relativism in action. Psychology of Sport and Exercise, 10, 491-497

Storry, T. (2003). The games outdoor adventurers play. In B. Humberstone, H. Brown, \& K. Richards (Eds.), Whose journeys? The outdoors and adventure as social and cultural phenomena (pp. 201-228). Penrith: The Institute for Outdoor Learning. 
van Manen, M. (1997a). From meaning to method. Qualitative Health Reseach, 7(3), 345369.

van Manen, M. (1997b). Researching lived experience: Human science for an action sensitive pedagogy (2nd ed.). London, Ontario: The Althouse Press.

Welser, H. T. (1997). Finding Life: The meanings of climbing to dedicated climbers. Masters, Miami University, Oxford, Ohio.

Wheaton, B. (2007). After sport culture: Rethinking sport and post-subcultural theory. Journal of Sport and Social Issues 31, 283-307. doi: 10.1177/0193723507301049

Willig, C. (2008). A phenomenological investigation of the experience of taking part in 'Extreme Sports'. Journal of Health Psychology, 13, 690-702.doi:

$10.1177 / 1359105307082459$

Willis, P. (2001). The 'Things Themselves' in phenomenology. Indo-Pacific Journal of Phenomenology, 1(1), 1-16.

Winstead, C. W. (1996). An existenial-phenomenological approach to an inner experience of contemporary american rock climbers. Doctoral thesis, California Institue of Integral Studies, CA.

Yakutchik, M. (1995). A grand lesson: For a first time mountaineer, life's limitations vanish into thin air. Women's Sport and Fitness, 17, 82-83. 